\title{
Analysis of Ultimate Load-Carrying Capacity of Combined Connection with Bolts and Welds
}

\author{
Tao LAN*,**, Jinsan JU***, Mengsha LIU**** \\ *CSIC International Engineering Co. Ltd, No.1 Shuangqiao Zhong Lu Beiyuan, Chaoyang District, Beijing 100121, \\ China, E-mail:qd_lantao@163.com \\ **CSIC Co. Ltd, No.72 Kunminghu Nan Lu, Haidian District, Beijing 100097, China, E-mail: qd_lantao@163.com \\ ***College of Water Resources and Civil Engineering, China Agricultural University, Qinghuadonglu No.17, Haidian \\ District, Beijing 100083, China, E-mail: jujinsan@cau.edu.cn \\ ****College of Water Resources and Civil Engineering, China Agricultural University, Qinghuadonglu No.17, Haidian \\ District, Beijing 100083, China, E-mail: liumengsha@cau.edu.cn \\ crossref http://dx.doi.org/10.5755/j01.mech.25.6.24791
}

\section{Nomenclature}

$P$ - Preload of bolt, $\mathrm{N} ; \mu$ - Friction coefficient; $N_{c}$ - total force due to contact pressure between plates, $\mathrm{N} ; N_{f}$ - total force due to frictional stress between plates, $\mathrm{N} ; N_{t}$ - theoretical value of slip bearing capacity, $\mathrm{N} ; f_{\text {bolt }}$ - ultimate bearing capacity of bolt joint, $\mathrm{N} ; f_{\text {weld }}$ - ultimate bearing capacity of welded joint, $\mathrm{N} ; f_{\text {bolt in combined }}$ - bearing capacity performed of bolts in combined connection, $\mathrm{N}$; $f_{\text {weld in combined }}$ - bearing capacity performed of welds in combined connection, $\mathrm{N}$; $d_{\text {welds in combined }}$ - average value of the relativity deformation of the weld along the length of the weld in combined joints, um; $d_{\text {welded }}$ - average value of the relativity deformation of the weld along the length of the weld in welded joints, um; $N_{\text {bolt in combined }}$ - total force due to contact pressure between plates in combined joints, $\mathrm{N} ; N_{\text {bolt }}$ - total force due to contact pressure between plates in bolt joints, $\mathrm{N}$.

\section{Introduction}

High-strength bolts connection and welds connection are common used in steel constructions. High-strength bolts work as a slip-critical connection at factored loads because of the fastener tension of bolts [1]. The bearing capacity of welded joints is determined by the physical attributes of weldment including material and geometric issues [2]. Although the high-strength bolts and welds work in different principles in steel structure connections, it is found in some studies that they can work together and show good performance [3-5]. Provisions for the design of combination joints with bolts and welds can be found in some existing specifications. The bearing capacity of a combined connection is the sum of the capacity of each individual element is clearly not conservative but is desired situation. The provisions in specifications [6] are derived conservatively from summarization of existing studies about the strength of joints that combine bolts and welds.

The American specification [7] stipulates that Bolts shall not be considered as sharing the load in combination with welds, except in the design of shear connections on a common faying surface where strain compatibility between the bolts and welds is considered. It is permitted to determine the available strength of a joint combining the strengths of a joint combining the strengths of high-strength bolts and longitudinal fillet welds as the sum of the nominal slip resistance for bolts and the nominal weld strength but multiplied by reduction factor $\varphi=0.75$ (LRFD) or divided by 2 (ASD). And the strength contribution ratio of bolts and welds in the required strength of the connection are stipulated respectively.

Like the provisions in AISC, the similar design proposal about the combined connection with high-strength bolts and welds is given in Chinese steel structure specification [8]. In combined joints, the slip-critical bearing capacity of high-strength bolts is only considered. The structure specification is also proposed that the high-strength bolts shouldn't be work together with transverse welds. The design formula is given in Chinese specification when the friction-type high-strength bolts are combined with longitudinal welds. The design formula put forward in JGJ 82-2011 used the study results of Hou Z. X. [9]. It' s found in the study of Hou Z. X that the strength of longitudinal welds and the bearing capacity of the high-strength bolts before slipping can be fully used in the combined joints with experimental method and the FEM is adopted in this research. The feasibility of numerical simulation is validated by comparing with test.

Japanese scholars [10] have carried out a detailed experimental study on the joints that combined highstrength bolts and welds. This study points out that the capacity of bolts after slipping shouldn't be considered and the transverse welds can't work well together with the highstrength bolts. But in the joints combined bearing-type highstrength bolts and longitudinal welds with respect to the direction of loading, the ultimate strength of the combined connection is the sum of the ultimate strength of each individual element. The American scholars [11] obtained the conforming conclusions with JSSC in 1977 through the study in experiment of different configurations of combination joints.

Some Chinese scholars [12-14] have studied the working behaviour of the joints combined high-strength bolts and welds with finite element method. The availability of FEM in bolts and welded joints is verified through these study because the bearing capacity and deformation characteristic of the FEM results have a higher consistency with the tests results. In them researches, the strength of welds in combined connection is supposed fully used when the ultimate strength of each individual element are close, the contribution of high-strength bolts to bearing capacity is very close to what was expected, otherwise the bolts contributed substantially less load resistance than was anticipated. 
In some studies, especially in experimental studies [15], the performances of bolts and welds in combined joints haven't been analyzed and only the bearing capacity is gotten. But it's found in this research that the connecting plates failed sometimes before bolts and welds even the geometry is designed exactly according to the provisions, because the strength of connection has to be higher than the plates in design.

In previous studies, it has reached an agreement that the strength of high-strength bolts after slipping can't be considered and the transverse welds shouldn't be used in combined joints. The working-together behavior can be considered in the joints that combined friction type highstrength bolts and longitudinal welds. Most of existing studies are macroscopic study and what they concern is the value of bearing capacity of combined connections. The bearing capacity of combined connections is affected by many factors, such as the geometric dimensions of the connected member, load sharing ratio of bolts and welds, bolt arrangement, and so on. However, scholars have not been able to reach a satisfactory agreement about mechanical behavior of combined connections and less research has been done. The finite element method is used in this research to reveal the working principle of the joints combined with bolts and welds.

\section{Finite Element Analysis}

\subsection{General}

The numerical analysis models of joints are established in ABAQUS and carry out numerical calculation and post-processing in this study. The tensile properties of tension lap splices that have both welds and bolts acting in the same shear plane are calculated by FEM and that of the joins with individual fastening elements of welds and bolts are also analyzed. A series of configurations of combination joints are analyzed in this research.

\subsection{Parametric variables and geometry}

The parametric investigated include the number of high-strength bolts and longitudinal welds' length and height in combined joints. According to the geometric provisions about the joints that combined high-strength bolts and longitudinal welds in Chinese steel structure specification (JGJ 82-2011, 2011), the geometry of the combined joints is determined. Two, three or four $20 \mathrm{~mm}$ diameter high-strength bolts are combined with longitudinal welds in different length and height that are used to connect $18 \mathrm{~mm}$ thick main and $14 \mathrm{~mm}$ thick lap plates of the splice. The geometry is shown in Fig. 1, where approximate locations of longitudinal welds are shown. The geometry of bolt can refer to "Manufacturing Manual of Steel Connections" [16].

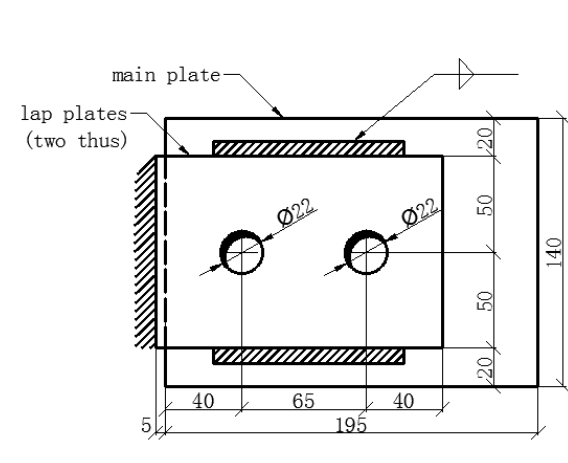

a

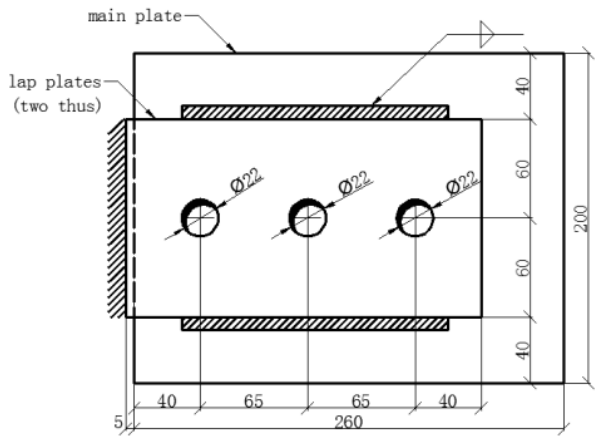

b

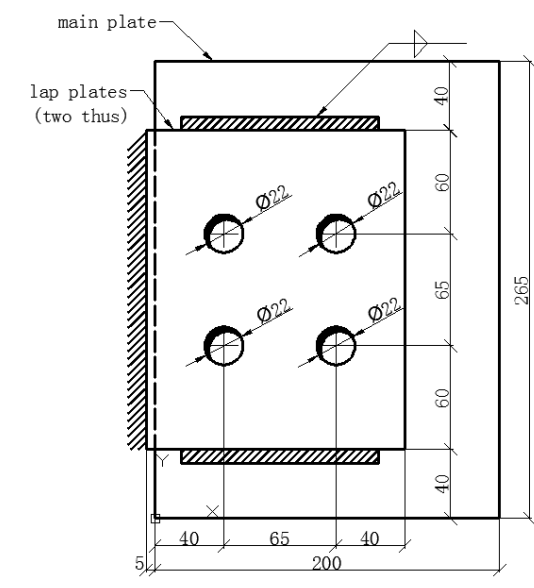

C

Fig. 1 Geometry of joints: a - two bolts, $\mathrm{b}$ - three bolts, $\mathrm{c}$ - four bolts

\subsection{Finite Element Model}

Detailed finite element model is developed with three dimensional solid elements in ABAQUS. The finite element model is shown as Fig. 2 taking two-bolts combined joint for example. Bolts, welds and plates are modelled separately and fitted together by defining interaction between

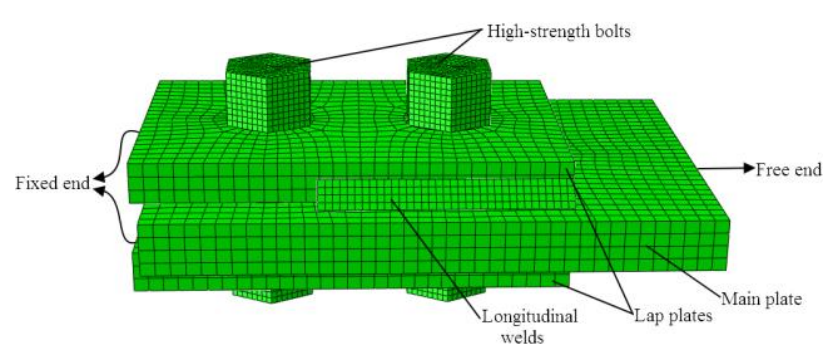

Fig. 2 Finite Element Model of the combined joint contact surfaces. The destruction of screw threads won't take place as bolts in double shear, so screw and nut are set up in one part without regard to threads. "Tie" constraints are applied in contact surfaces between plates and welds to simulate welded. Friction coefficient is 0.7 between main plate and lap plates to ensure high-strength bolts working.

C3D8R (8 nodes reduced integration solid elements) was chosen as the solid elements.

The material properties of welds, bolts and plates used in this study mainly reference to the study of Hou Z. X. [9]. In the study of Hou Z. X. [9], the mechanical properties of combined connections with welds and bolts were tested and based on the geometric data and material property obtained through tests, numerical analyses are carried out. The study of Hou Z. X. [9] show that the the numerical simulations carried out in Hou's study can estimate the tests results exactly, no matter the deformation or bearing capacity of the 
joints, and part of the results are shown in Fig. 3. The material of welds, bolts and steel plates adopted in Hou's study are common used material shown as Table 1 and all material parameters are obtained by material test. The performance of the joints after the material of plates and bolts enters the yield is not studied in this paper. Therefore, the same material properties with Hou's study are adopted in this study, as shown in Table 1.

Two static analysis steps are created for applying loads. The $125 \mathrm{kN}$ preload is applied on high-strength bolts in the first step. The welds' elements are deactivated in first step and reactivated in second step to simulate the process for welding after bolt pretension. In second step, the main plate is tensioned on its free end until the joint failure and the lap plates are clamped on its' fixed end.
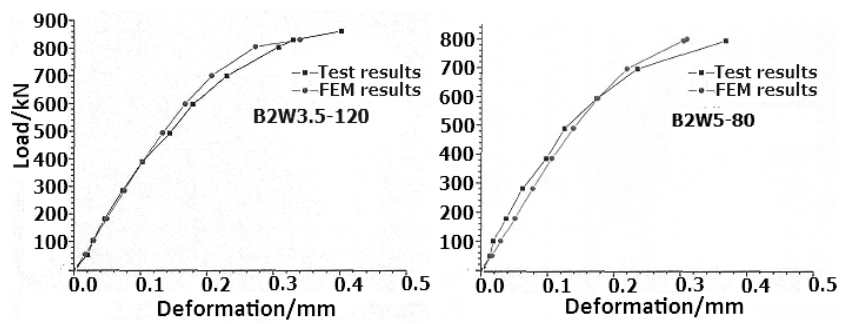

Fig. 3 The results in study of Hou Z. X. [9]

Material Property Adopted in FEM

\begin{tabular}{|c|c|c|c|c|}
\hline Component & Density, $\mathrm{kg} / \mathrm{m}^{3}$ & Elasticity modulus, MPa & Poisson's ratio & Yield strength, MPa \\
\hline High-strength bolt & 7800 & 206000 & 0.30 & 940 \\
\hline Longitudinal weld & 7800 & 900000 & 0.30 & 385 \\
\hline Steel plate & 7800 & 206000 & 0.30 & 345 \\
\hline
\end{tabular}

\section{Numerical simulation}

The simulation is carried out in two steps as is described above. The Mises stress distribution of the joint at the end of first analysis step is shown in Fig. 4. Bolt load cause the bolts rod elongated and plates interact with each other by $250 \mathrm{kN}$ due to contact pressure.

The mechanical behaviour of the joint of two highstrength bolts combined with four $8 \mathrm{~mm}$-high and $87 \mathrm{~mm}$ long welds (The specimen number is B2W08087.) is studied in this section as an example and the other configurations of joints are analyzed like this joint. Besides the combined joints, the joins with individual fastening elements are also modelled and calculated. Load versus deformation results are shown in Fig. 5.

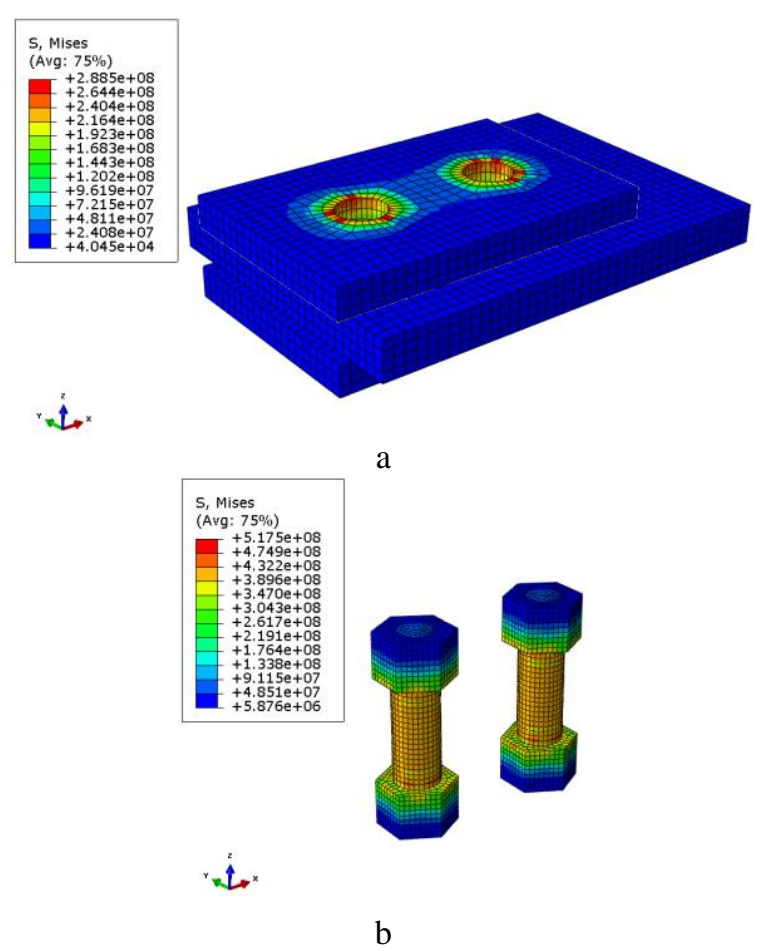

Fig. 4 Mises stress cloud charts at the end of first analysis step: a - stress distribution of plates, b - stress distribution of bolts

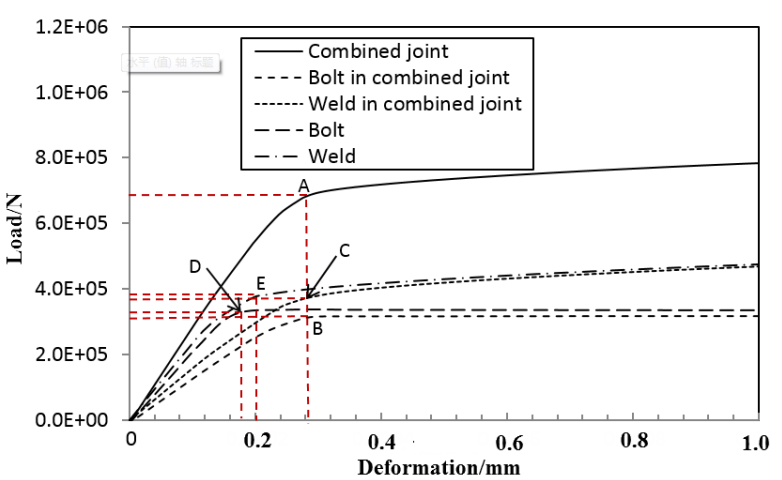

Fig. 5 Load versus deformation of the joint analyzed

The load shown in Fig. 5 of combined joint and weld curves is reaction force at the fixed end; frictional force between plates is extracted as the load bolt bearing. The deformation is the displacement of the free end. The weld in combined joint curve is gotten by the combined joint curve minus the bolt in combined curve. The curve shown in Fig. 5 named by "Combined joint" represents the load versus deformation of the combined joint whose specimen number is B2W08087, and the curves named by "Bolt in combined joint" and "Weld in combined joint" give the performance of bolts and welds in that combined joint respectively. The curve named by "Bolt" represents the load versus deformation of the joint with individual fastening element of two high-strength bolts, and the "Weld" curve represents that of the joint with individual fastening element of four $8 \mathrm{~mm}$ high and $87 \mathrm{~mm}$-long welds.

The bearing capacity after slipping between plates of high-strength bolts is unconsidered in this study. Therefore, the point where the deformation suddenly increases in the load-deformation curve of bolt represents failure, shown as point D in Fig. 5. The slip bearing capacity of joints connected by different number of bolts is shown in Table 2. $N_{c}$ and $N_{f}$ in Table 2 are extracted from numerical simulation results, and $N_{f}$ is considered as the bearing capacity of the joints connected by bolts. The error between theoretical value and slip bearing capacity increases with the number of bolts according to Table 2 which is considered is caused by loading not evenly on each bolt rather than inaccurate calculation. 
Table 2

The bearing capacity of the joints connected by bolts

\begin{tabular}{|c|c|c|c|c|c|c|}
\hline Number of bolts & $P$ & $\mu$ & $N_{c}$ & $N_{f}$ & $N_{t}$ & Error \\
\hline 1 & $1.250 \mathrm{E}+05$ & 0.7 & $1.250 \mathrm{E}+05$ & $1.708 \mathrm{E}+05$ & $1.750 \mathrm{E}+05$ & $2.39 \%$ \\
\hline 2 & $1.250 \mathrm{E}+05$ & 0.7 & $2.500 \mathrm{E}+05$ & $3.375 \mathrm{E}+05$ & $3.500 \mathrm{E}+05$ & $3.56 \%$ \\
\hline 3 & $1.250 \mathrm{E}+05$ & 0.7 & $3.804 \mathrm{E}+05$ & $4.984 \mathrm{E}+05$ & $5.250 \mathrm{E}+05$ & $5.07 \%$ \\
\hline 4 & $1.250 \mathrm{E}+05$ & 0.7 & $5.054 \mathrm{E}+05$ & $6.560 \mathrm{E}+05$ & $7.000 \mathrm{E}+05$ & $6.28 \%$ \\
\hline
\end{tabular}

Note: The design formula of theoretical value of slip bearing capacity is $N_{t}=n \mu P$, in this study, the number of friction surface $n=2$.

The damage of the welded is shown up as a yield zone from one end to the other, which is shown as Fig. 6. The yield zone appears when the load-deformation curve of weld has an inflection point, shown as point $\mathrm{E}$ in Fig. 5. In the same way to judge the failure of connection in the combined joint, it can be found that the slip between plates and the appearance of the yield zone in weld are almost simultaneous which can also have observed from Fig. 5. Point B represents the failure of high-strength bolts in combined joint and Point $\mathrm{C}$ represents the welds.
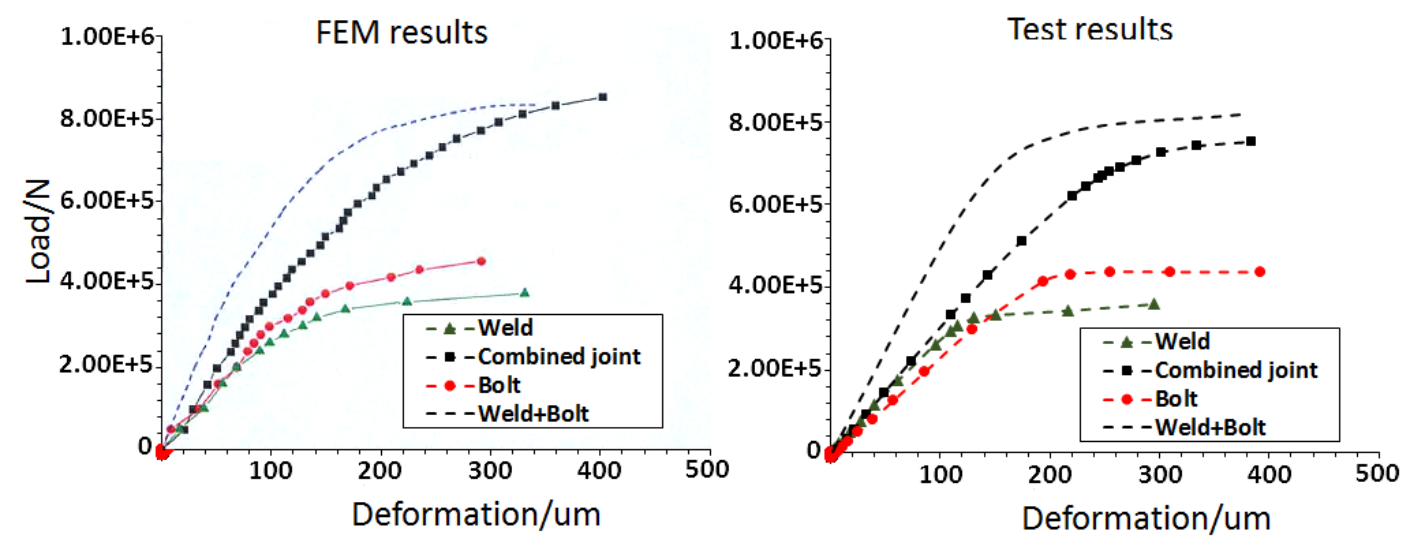

a

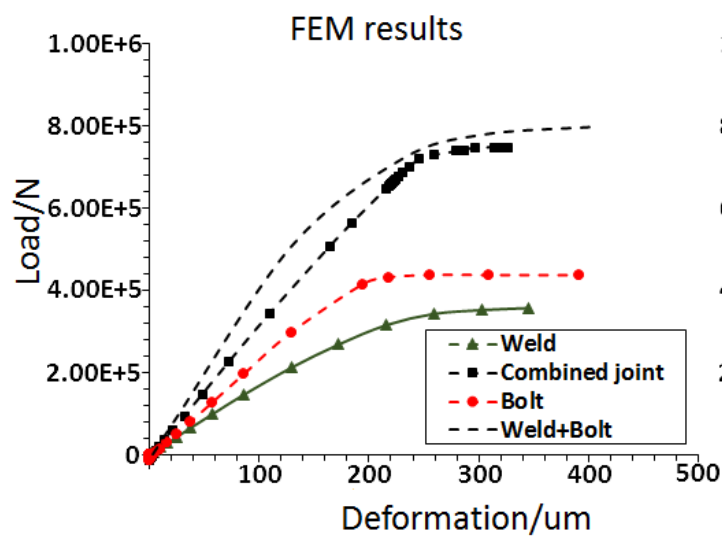

b

Fig. 7 Comparison of tests and numerical calculation results: a - load versus deformation of the joint B2W3.5-120 (two highstrength bolts combined with four $3.5 \mathrm{~mm}$-high and $120 \mathrm{~mm}$-long welds. The $160 \mathrm{kN}$ preload is applied on highstrength bolts); $\mathrm{b}$ - load versus deformation of the joint B2W5.0-120 (two high-strength bolts combined with four 5.0 mm-high and $120 \mathrm{~mm}$-long welds. The $160 \mathrm{kN}$ preload is applied on high-strength bolts)

The shape of load-deformation curves calculated by the finite element model established in this research are in good agreement with the test results (Hou Z. X., 2012) and part results are shown in Fig. 7 for comparison. The curves 'legends in Fig. 7 have the same meaning with that in Fig. 5, in addition, the curves named by "Weld+Bolt" is gotten by summing the load of "Weld" and "Bolt" at the
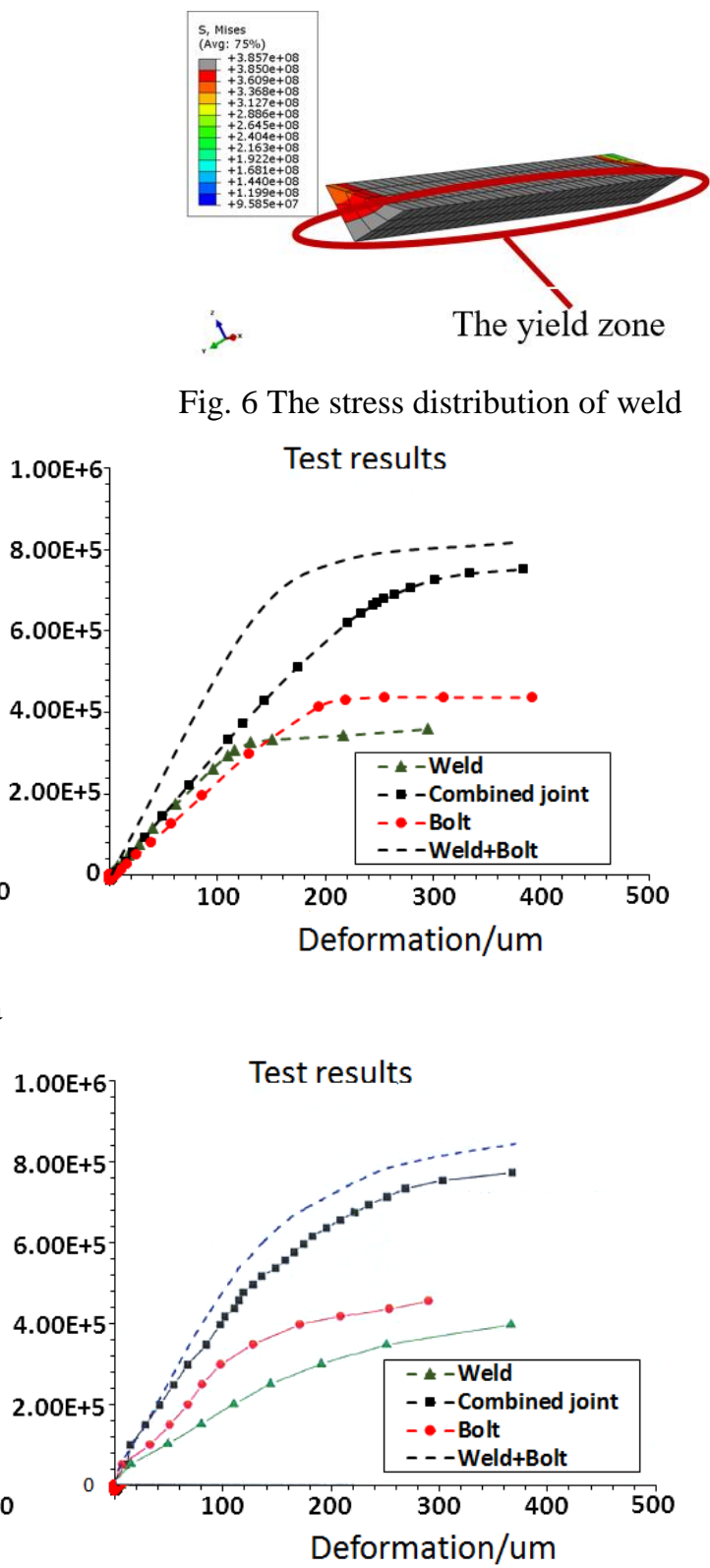

Fig. 6 The stress distribution of weld

same deformation. It can be observed from both FEM results and test results that the load is increase with the increase of the deformation in tension lap splices and the slope of load-deformation curve is decreasing. The inflection point on the load-deformation curves like point $A$, point $D$ and point E shown in Fig. 5 can be found in both FEM re- 
sults and test results shown in Fig. 5 and it shows better deformation ability in combined connection than in bolts joint and welds joint. The good agreement between FEM results and test results indicates the established numerical model is correct and reliable.

Calculation results are handled as above and the mechanical behaviour of combined joints is analyzed. Thirty combined joints with different configurations are studied and partial results are shown in Table $3 . K_{\text {strength }}, R_{\text {bolt }}$ and $R_{\text {weld }}$ shown in Table 3 are coefficients to describe interaction behaviour whose calculation formulas are shown in Eqs. (1), (2) and (3) respectively.

$$
\begin{aligned}
& K_{\text {strength }}=f_{\text {bolt }} / f_{\text {weld }}, \\
& R_{\text {bolt }}=f_{\text {bolt in combined }} / f_{\text {bolt }}, \\
& R_{\text {weld }}=f_{\text {weld in combined }} / f_{\text {weld }},
\end{aligned}
$$

where: $f_{\text {bolt }}$ and $f_{\text {weld }}$ represent the ultimate bearing capacity of joint with individual fastening elements and $f_{\text {bolt in combined }}$ and $f_{\text {weld in combined }}$ represent the capacity caused by bolts and

welds in combined joints when the joints fail. So it can be considered bolts can work well with welds when $R_{\text {bolt }}$ and $R_{\text {weld }}$ are both close to 1 . $R_{\text {bolt }}$ and $R_{\text {weld }}$ of the most configurations of combined joints are relatively high and greater than 0.9. The results of the combined joints in lower $R_{b o l t}$ and $R_{\text {weld }}$ are listed in Table 3 . There is little comparability of the specimens shown in Table 3 such as in number of bolts, the size of longitudinal welds or $K_{\text {strength }}$. But it could be found by comparing the ultimate bearing capacity of the 30 combined connections, the combined joints in lower $R_{\text {bolt }}$ and $R_{\text {weld }}$ shown in Table 3 are all in higher ultimate bearing capacity. It's supposed that the plates are failure before bolts and welds. The study is projected forward based on the nondestructive of plates by defining the material properties of plates in elasticity in next section.

\section{Bearing capacity mechanism study}

Supposing the material of plates is linear-elastic in this section, the large deformation of the joints is caused by the failure of bolts or welds. The handling of FEM results can refer to the above section. Besides, the mechanical behaviours of the welds and bolts are carried out.

Table 3

The partial results of the combined joints

\begin{tabular}{|c|c|c|c|c|c|c|c|}
\hline $\begin{array}{c}\text { Specimen } \\
\text { number }\end{array}$ & $\begin{array}{c}\text { Number of } \\
\text { bolts }\end{array}$ & $\begin{array}{c}\text { Height of longitu- } \\
\text { dinal welds, mm }\end{array}$ & $\begin{array}{c}\text { Length of longitu- } \\
\text { dinal welds, mm }\end{array}$ & $\begin{array}{c}\text { Ultimate bearing } \\
\text { capacity, N }\end{array}$ & $K_{\text {strength }}$ & $R_{\text {bolt }}$ & $R_{\text {weld }}$ \\
\hline B2W08145 & 2 & 0.008 & 0.145 & $8.383 \mathrm{E}+05$ & 0.4703 & 0.7485 & 0.8160 \\
\hline B2W10145 & 2 & 0.010 & 0.145 & $8.318 \mathrm{E}+05$ & 0.4562 & 0.8814 & 0.7221 \\
\hline B3W08210 & 3 & 0.008 & 0.210 & $9.425 \mathrm{E}+05$ & 0.5858 & 0.6464 & 0.7297 \\
\hline B3W10126 & 3 & 0.010 & 0.126 & $1.007 \mathrm{E}+06$ & 0.7847 & 0.8493 & 0.9196 \\
\hline B3W10210 & 3 & 0.010 & 0.210 & $1.164 \mathrm{E}+06$ & 0.4600 & 0.6768 & 0.7635 \\
\hline
\end{tabular}

Note: The letter "B" represents the number of bolts in joints; B2 represents two bolts for examples. The letter "W" represents the size of the weld in joints; W08145 represents the $8 \mathrm{~mm}$-high and $145 \mathrm{~mm}$-long welds for examples

A yield zone on weld indicates the failure of the welds. The displacement difference between Line 1 and Line 2 shown as Fig. 8 along the direction of load represents the deformation of weld in this analysis. The displacement of each node on Line 1 and Line 2 are extracted when the weld failed and the subtraction is performed on these date.
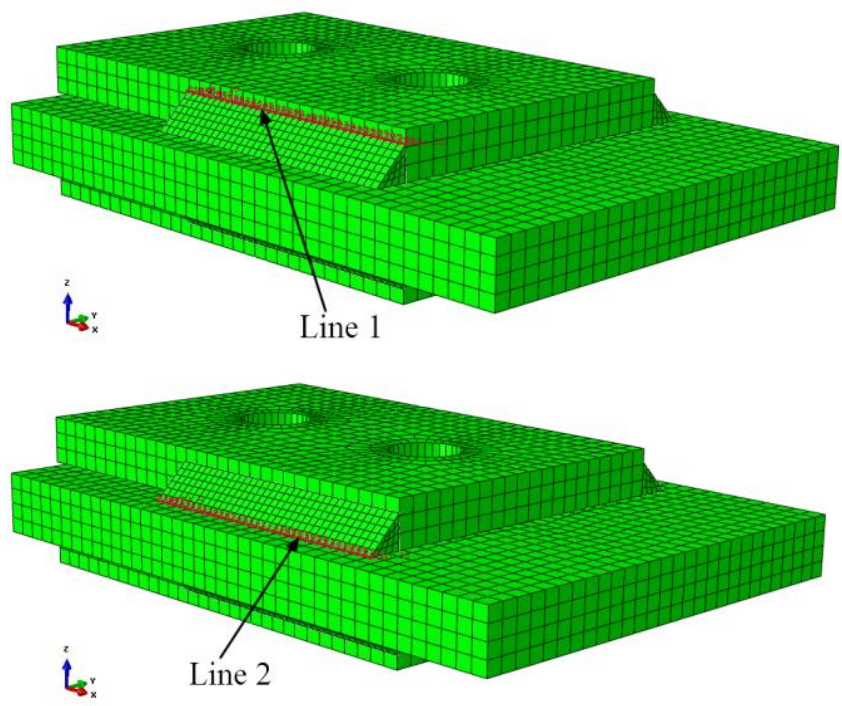

Fig. 8 The location of Line 1 and Line 2
The relative deformations of welds in welded joint and combined joint at the moment the joints failed are shown as Fig. 9. The relative deformations of welds shown in Fig. 9 are extracted from numerical simulation results when welds failed, that is, at the deformation state corresponding to point E shown in Fig. 11. Similarly, the relative deformations of the weld in combined joints are extracted at the deformation state corresponding to point A shown in Fig. 11.

Three graphs of different configurations are given in Fig. 9. It can be observed from Fig. 9 that the relative deformation is larger at the two ends of the weld than that at the middle of the welds. When the length of the weld is much smaller than the lap plates shown as Fig. 9, a, the relative deformation of the weld from one end to the other changes slightly. The relative deformation inhomogeneity along the length of the longitudinal welds became obvious with the increase of the ratio of the weld length to the length of lap plates' edge shown in Fig. 9, b and c. The relative slip between the plates is limited by the tightening effort of highstrength bolts and the relative deformation of the welds is also limited near the bolts, but it has little effect on the weld away from the bolts like the curves shown as Fig. 9, c. Because of the limit in the middle of the welds, the appearance of the yield zone is put off and the relative deformation of the welds away from the bolts in combined joints is larger than in welded joints which can observed from Fig. 9, b and Fig. 9, c. So the ultimate deformation capacity of welds is 
slightly greater in combined joints than in welded joints sometimes.

The distribution of interface friction stress on main plate when the joint failed is given in Fig. 10. It could be found that the friction stress away from the bolt holes and closed to the welding position is very small. Hence, the welds have little effect on the high-strength bolts when the joints are designed according to the geometric provisions about the joints that combined high-strength bolts and longitudinal welds in Chinese steel structure specification (JGJ 82-2011, 2011).

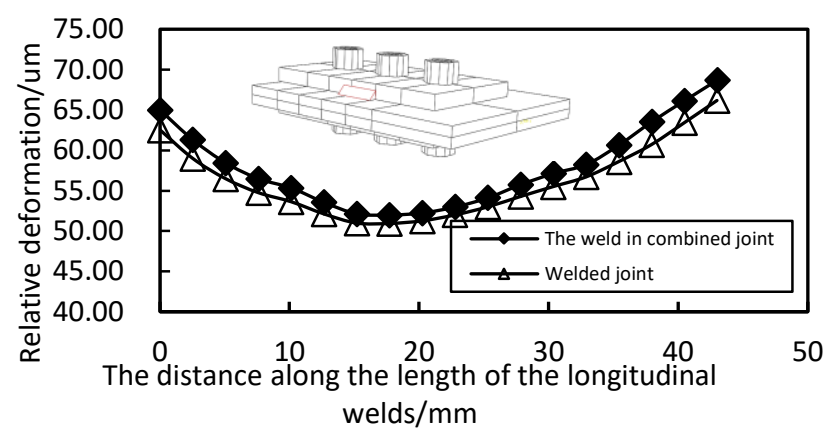

a

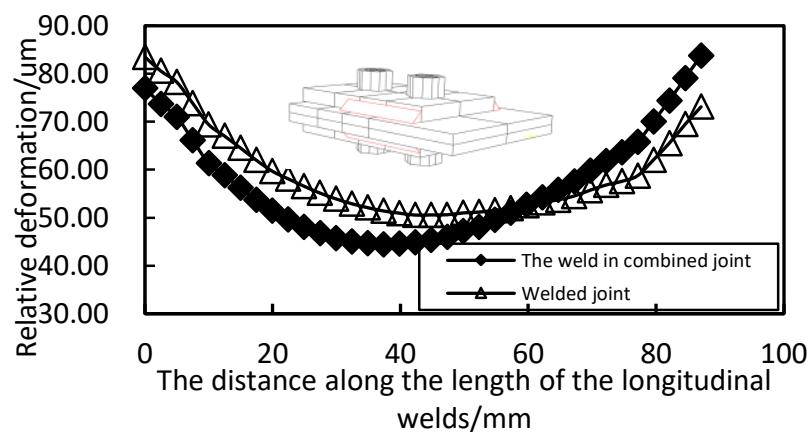

b

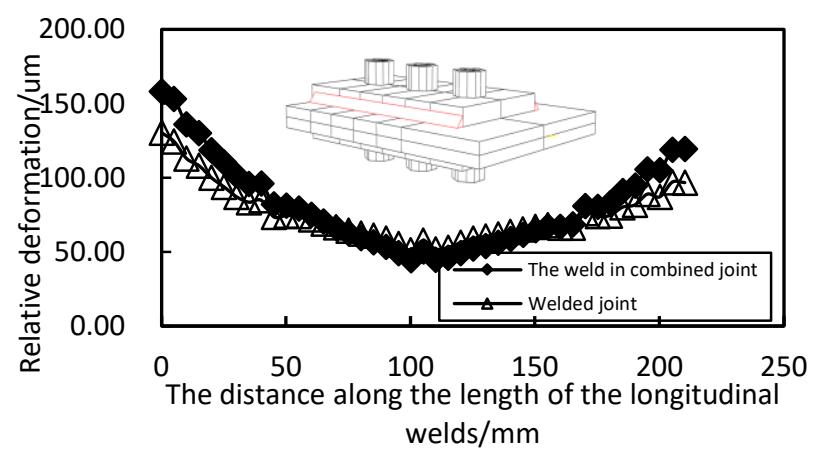

$\mathrm{c}$

Fig. 9 The relative deformations of welds in welded joint and combined joint: a - B3W08042, b - B2W10087, c - B3W08210

The load-deformation curve of B2W08087 in this section is shown in Fig. 11 whose analytical procedure can completely refer to Fig. 5 . The material property of plates is linear-elastic; hence the deformation of the joints is caused by the slipping between plates rather than the deformation of plates. In addition to the same conclusion as the previous section, it can be also reconfirmed that the deformation capacity of the combined joints is increased because of the combined effect of bolts and welds.

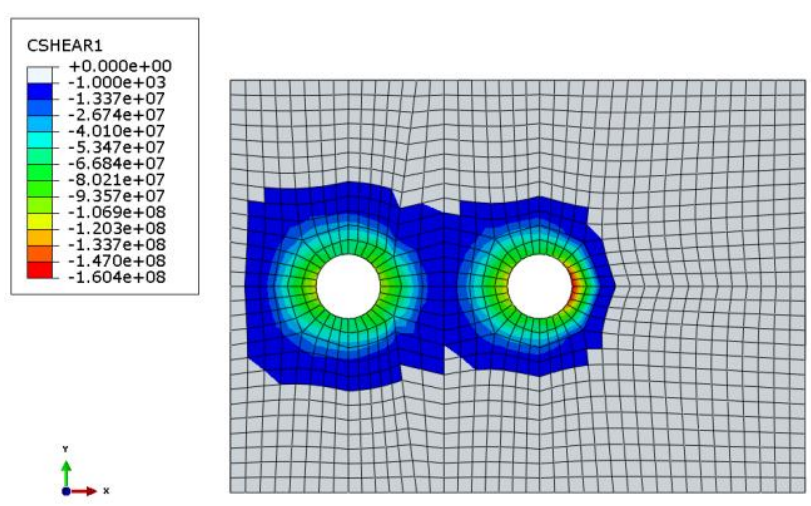

Fig. 10 The distribution of interface friction stress on main plate

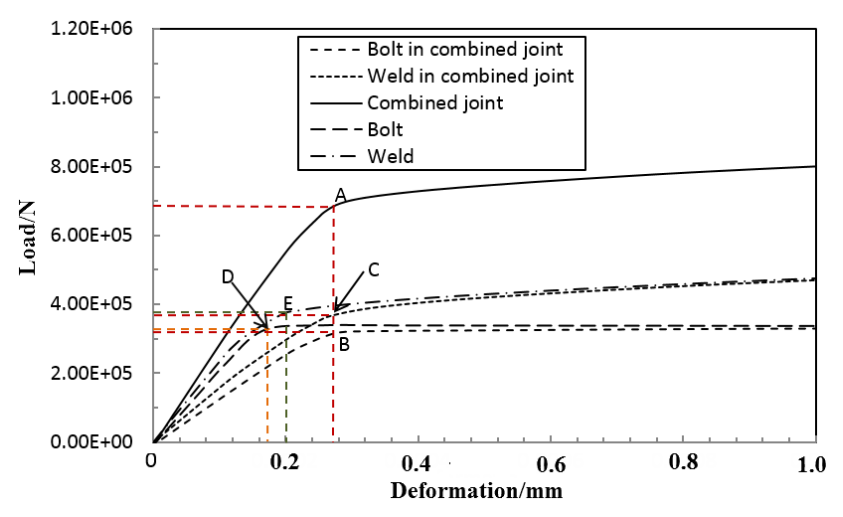

Fig. 11 Load versus deformation of the joint analysed

The data of all joints with different configurations analyzed in this section are shown in Table 4 . The calculation formulas of $K_{\text {strength }} . R_{\text {bolt }}$. and $R_{\text {weld }}$. are as same as the previous section and the formula of $R_{\text {bolt }} . K_{\text {deformation }}$ and

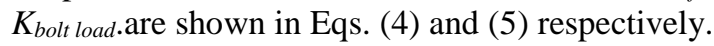

$$
\begin{aligned}
& K_{\text {deformation }}=d_{\text {welds in combined }} / d_{\text {welded }}, \\
& K_{\text {bolt load }}=N_{\text {bolt in combined }} / N_{\text {bolt }},
\end{aligned}
$$

where: $d_{\text {weld in combined }}$ and $d_{\text {welded }}$ represent the average value of the relativity deformation of the weld along the length of the weld in combined joints and welded joints respectively. $N_{\text {bolt in combined }}$ and $N_{\text {bolt }}$ are the total force due to contact pressure between plates in combined joints and bolt joints respectively. $R_{\text {bolt }}$ and $N_{\text {weld }}$ shown in Table 4 are greater than 0.9 which can prove the good interaction behaviour of bolts and welds in the combined joint. The work condition of welds in combined joints can be judged with the value of $K_{\text {deformation. }}$ When $K_{\text {deformation. }}$ is closed to 1.0 , it can be considered that the welds in combined joints give the same performance as in welded joins. It can be observed from Table 4 , the value of $K_{\text {deformation }}$ are almost closed to 1.0 and even more than 1.0. The value of $K_{\text {bolt load }}$. which is more close to 1.0 shown in Table 4 give the validation to the well-working condition of the bolts in combined joints.

It can be concluded that in the combined joints, the friction type high-strength bolts have a good working performance with longitudinal welds. 
Table 4

The data of all joints with different configurations

\begin{tabular}{|c|c|c|c|c|c|c|}
\hline Specimen number & Ultimate bearing capacity, $\mathrm{kN}$ & $K_{\text {strength }}$ & $R_{\text {bolt }}$ & $R_{\text {weld }}$ & $K_{\text {deformation }}$ & $K_{\text {bolt load }}$ \\
\hline B2W10145 & 1039.88 & 0.4557 & 0.9426 & 0.9721 & 0.9254 & 0.9365 \\
\hline B2W10087 & 749.98 & 0.6902 & 0.9151 & 0.9014 & 0.9571 & 0.9453 \\
\hline B2W10058 & 627.19 & 1.0950 & 0.9466 & 0.9974 & 1.2231 & 0.9561 \\
\hline B2W08145 & 1026.50 & 0.4302 & 0.9576 & 0.9564 & 0.7675 & 0.9145 \\
\hline B2W08087 & 692.13 & 0.8691 & 0.9903 & 1.0032 & 1.0935 & 0.9492 \\
\hline B2W08058 & 557.68 & 1.2915 & 0.9754 & 0.9719 & 0.8492 & 0.9641 \\
\hline B2W08035 & 467.94 & 2.1696 & 0.9841 & 1.0106 & 1.2081 & 0.9651 \\
\hline B2W06145 & 690.12 & 0.8997 & 0.9041 & 1.0253 & 1.2657 & 0.9526 \\
\hline B2W06087 & 592.61 & 1.2217 & 0.9513 & 0.9819 & 0.8688 & 0.9583 \\
\hline B2W06058 & 507.77 & 1.8189 & 0.9625 & 0.9844 & 0.9067 & 0.9691 \\
\hline B3W10210 & 1604.30 & 0.4347 & 0.9321 & 0.9917 & 0.9642 & 0.9288 \\
\hline B3W10126 & 1124.25 & 0.7518 & 0.9564 & 0.9738 & 0.9333 & 0.9537 \\
\hline B3W10084 & 968.50 & 1.0240 & 0.9676 & 0.9955 & 1.0010 & 0.9645 \\
\hline B3W08210 & 1324.92 & 0.5858 & 0.9458 & 1.0005 & 1.0727 & 0.9480 \\
\hline B3W08168 & 1159.42 & 0.7927 & 0.9547 & 1.0839 & 1.8505 & 0.9536 \\
\hline B3W08126 & 974.87 & 0.9722 & 0.9530 & 0.9717 & 0.7380 & 0.9670 \\
\hline B3W08084 & 848.76 & 1.3262 & 0.9596 & 0.9818 & 0.8532 & 0.9745 \\
\hline B3W08063 & 715.53 & 1.9556 & 0.9397 & 0.9649 & 0.8046 & 0.9853 \\
\hline B3W08052 & 683.85 & 2.3334 & 0.9552 & 0.9672 & 0.7381 & 0.9864 \\
\hline B3W08042 & 669.16 & 2.6523 & 0.9644 & 0.9969 & 1.0312 & 0.9835 \\
\hline B3W06210 & 1095.50 & 0.7722 & 0.9062 & 0.9946 & 1.0950 & 0.9603 \\
\hline B3W06126 & 867.72 & 1.2630 & 0.9604 & 0.9819 & 0.7978 & 0.9700 \\
\hline B3W06084 & 775.74 & 1.7717 & 0.9801 & 1.0162 & 1.2781 & 0.9769 \\
\hline B4W08065 & 916.21 & 2.6111 & 0.9883 & 1.0592 & 0.8657 & 0.9886 \\
\hline B4W08085 & 988.52 & 2.1579 & 0.9822 & 1.1261 & 1.0452 & 0.9877 \\
\hline B4W08095 & 1022.30 & 1.7130 & 0.9769 & 0.9910 & 1.0492 & 0.9868 \\
\hline B4W08105 & 1052.63 & 1.6224 & 0.9749 & 1.0166 & 1.2356 & 0.9878 \\
\hline B4W05140 & 1161.72 & 1.2663 & 0.9696 & 1.0104 & 1.2845 & 1.0057 \\
\hline
\end{tabular}

\section{Conclusions}

The mechanical behaviour of the combined connection with high-strength bolts and longitudinal welds is studied sufficiently with finite element method in this study. The bearing capacities produced by bolts and welds in combined joints are gotten respectively taking the advantage of FEM and the whole-working history analysis have been conducted. The failure of plates is supposed not happened in this research to study the mechanical behaviour of bolts and welds directly. The particular conclusions are as follow:

1. The failure of welds shown as the appearance of yield zoon from one end to the other on the weld. The working condition of high-strength bolts is estimated according to the interaction between plates. The displacement ductility of the combined joints is increased compared to weld and bolt joints because of the combined effect of bolts and welds and the ultimate bearing capacity of welds is slightly greater in combined joints than in welded joints due to the restriction of welds' deformation caused by the fastening of high-strength bolts.

2 . The strength of weld and the bearing capacity of the high-strength bolts before slipping can be efficiently used in the combined joints when the geometry of plates connected is large enough as the geometric provisions in specifications (JGJ 82-2011, 2011) for the plates connected by high-strength bolts to ensure the bolts and welds' working performances are not affected by each other. The bolts and welds in combined connections fail almost simultaneously.

\section{Acknowledgements}

Support for this research by the project Research and Application of Key Technology of Prefabricated Steel Structure Building (201815K) that is approved by CSIC Co. Ltd. This work was also financially supported by National Science Foundation of China (51279206).

\section{References}

1. Geoffrey, L. K.; Scott, T. U. 1998. Tension control bolts: strength and installation, Journal of Bridge Engineering 3(1): 15-20.

http://dx.doi.org/10.1061/(ASCE)10840702(1998)3:1(1 5).

2. Kang, H.; Barkey, M. E.; Lee, Y. 2000. Evaluation of multiaxial spot weld fatigue parameters for proportional loading, International Journal of Fatigue 22(8): 691-702. http://dx.doi.org/ 10.1016/S0142-1123(00)00037-2.

3. Liu, S. Y. 1985. Analysis of mechanical properties of high strength bolt and weld joint, Industrial Architecture 15(6): 24-27.

http://dx.doi.org/10.13204/j.gyjz198506007.

4. Chang, H. Y.; Yeh, C. Y. 2019. A study on behavior of steel joints that combine high-strength bolts and fillet welds, Steel and Composite Structures 31(4): 361-372. http://dx.doi.org/10.12989/scs.2019.31.4.361.

5. Shi, Y. J. 2013. Proposed design method of combined connections with bolts and longitudinal welds for steel structures, Industrial Construction 94-96(3): 923-928. 
http://dx.doi.org/10.4028/www.scientific.net/AMM.9496.923.

6. Standard AISC. 2016. Specification for Structural Steel Buildings. J1.9: Bolts in Combination with Welds. American Institute of Steel Construction, Chicago.

7. Standard BS. 2005. EN 1993-1-8:2005. Eurocode 3: Design of Steel Structure-Part 1-8: Design of Joints. British Standards Institution, London.

8. Standard JGJ 82-2011. 2011. Technical specification for high strength bolt connection of steel structures. 5.4: Joints combined bolts and welds. China Building Industry Press, Beijing.

9. Hou, Z. X. 2012. High strength bolt connection design and construction, China Building Industry Press, Beijing: 154-172.

10. Standard JSSC. 1977. HIGH-STRENGTH BOLTS: 8. combined joints. Japanese Society of Steel Construction.

11. Manuel, T. J.; Kulak, G. L. 1998. Strength of joints that combine bolts and welds, Journal of Structural Engineering 126(3): 279-287. http://dx.doi.org/10.1061/(asce)07339445(2000)126:3( 279).

12. Ma, J. S.; Wang, Y. Q.; Li, M. F.; Bai, R. S.; Ban, H. Y. 2017. Discussion on Influence of High Strength Bolt's Parameters on the Weld Reinforced Combined Connection with Bolts and Welds. IOP Conference Series: Earth and Environmental Science. http://dx.doi.org/10.13206/j.gjg201804003.

13. Shi, Y. J.; Wang, L.; Wang, Y. Q.; Ma, J. S.; Bai, R. S. 2011. Finite element analysis of the combined connection with bolts and welds, Applied Mechanics \& Materials 94-96: 316-321. http://dx.doi.org/10.4028/www.scientific.net/AMM.9496.316.

14. Liu, M. S.; Li, C. A.; Huang, J. R.; Ju, J. S. 2016. Numerical modeling and mechanical analysis of combined connection with bolts and welds, Strength of Materials 48(6): 862-869. http://dx.doi.org/10.1007/s11223-017-9832-1.

15. Guo, Y. M.; He, X. J.; Liu, G. L. 1996. Research on connecting behaviour and processor weld-bolt hybrid joint, Steel Construction 3(33): 50-55.
16. Wang, K. N.; Yu, H. 2015. Manufacturing Manual of Steel Connections. China Machine Press, Beijing.

Tao Lan, Jinsan Ju, Mengsha Liu

\section{ANALYSIS OF ULTIMATE LOAD-CARRYING CAPACITY OF COMBINED CONNECTION WITH BOLTS AND WELDS}

S u m m a r y

In this paper, load-carrying and deformation capacity of tension lap splices that have both welds and bolts acting in the same shear plane are studied using numerical method. The failure criterion of bolts and welds are given based on the finite element calculation and compared with existing experiment results, it shows that the established numerical model is correct and reliable. The strength of longitudinal welds and the bearing capacity of the high-strength bolts before slipping can be fully used in the combined joints, the bolts and welds fail almost simultaneously. The deformation of welds in combined connections is less uniform than its' deformation in welded joints as the welds fails, and it causes the deformation of welds as failure is larger in combined connections than in welded connections. The deformation capacity of the combined joint are slightly increased contrasted with bolts joint and welds joint because of the interplay of bolts and welds acting in the same shear plane. The strengths of welds and bolts performed in combined connections can reach 0.95 and the deformation of combined connection is increased at least 1.10 times as the welds connection or the bolts connection.

Keywords: lap splices; combined connection; load-carrying capacity; deformation capacity.

Received May 10, 2019

Accepted November 21, 2019 